\title{
The Contribution of Educated Workers to Firms' Efficiency Gains: The Key Role of Proximity to the 'Local' Frontier
}

\author{
V. Vandenberghe ${ }^{1}(\mathbb{D}$
}

Published online: 26 May 2018

(C) Springer Science+Business Media, LLC, part of Springer Nature 2018

\begin{abstract}
Vandenbussche et al. (J Econ Growth 11(2):97-127, 2006) and Aghion et al. (in: Romer, Wolfers (eds) Brookings papers on economic activity: conference draft, Brookings, Washington, 2009) show that when economies operate close to the technological frontier, their ability to generate efficiency gains rests on the contribution of workers with advanced forms of education (i.e. tertiary). The contribution of this empirical paper is to revisit and improve the analysis of that assumption, in the context of firms located in advanced economics, assuming that what holds for OECD countries or US states should also be observed also at a more disaggregated level. To that end, we analyse a rich panel of Belgian firm-level data, covering the 2008-14 period. In the first step, we estimate each firm's proximity to frontier using stochastic frontier methods. Step 2 consists in regressing each firm's efficiency growth rate on (1) the share of workers by education attainment (2) its (initial) distance/proximity to the frontier and (3) (the main variable of interest) the interaction between (1) and (2), whose sign provides a direct test of the Vandenbussche/Aghion assumption. The main result of the paper supports the idea that the closer the firms are to what amounts to a local frontier; the more educated workers - in particular those with a master's degree-matter for efficiency gains. The paper also shows that many of them are currently employed in firms that are distant from the efficiency frontier. Reallocating them would have a positive impact on overall efficiency.
\end{abstract}

Keywords Efficiency growth · Highly-educated workers · Frontier firms · Proximity to frontier

JEL Classification $\mathrm{J} 24 \cdot \mathrm{I} 20 \cdot \mathrm{E} 24 \cdot \mathrm{O} 30 \cdot \mathrm{O} 40$

\footnotetext{
$\bowtie \quad$ V. Vandenberghe

vincent.vandenberghe@uclouvain.be

1 IRES, Université Catholique de Louvain (UCL), 3 Place Montesquieu, 1348 Louvain-la-Neuve, Belgium
} 


\section{Introduction}

Productivity plays a key role not only in the prosperity of countries but also in the success of firms. In practice, its level varies enormously across entities. Those forming the frontier cohabit with "laggards" (Andrews et al. 2015). In dynamic terms, productivity growth depends on the ability of the frontier entities to lift the frontier further up, but also - and perhaps more significantly — on the capacity of all the other entities to catch up and converge towards the frontier. Not surprisingly, there is a large economic literature on productivity convergence between countries (Barro and Sala-i-Martin 1997; Aghion and Howitt 1992; Howitt 2000), and an emerging literature on convergence between firms (Bartelsman et al. 2008; Andrews et al. 2015).

The theoretical construct underlying the process of convergence is that of knowledge spillovers emanating from the most productive, or frontier, technology. To the extent that knowledge is non-rival and not fully appropriable, entities below the frontier can potentially improve performance by learning from the best. The learning process may be easy at first, but then proves more complicated beyond a certain threshold. What is more, there might exist various factors facilitating/impeding that learning process, whose importance may increase the closer one tries to match the performance of the best. Nelson and Phelps (1966) were the first to suggest that education facilitates the implementation of new technologies and help countries catch-up with the leading country. They argued that the importance of human capital rises with the innovative content of the tasks performed or with the extent to which it is necessary to follow and to understand new technological developments, implement more complex procedures... They write: "At the bottom of this scale are functions that are highly routinized.... In the other direction on this scale we have, for example, innovative functions which demand keeping abreast of improving technology" (p. 69). Acemoglu et al. (2006) showed theoretically that innovation should be more important than adoption/replication as an economic entity approaches the technological frontier. Vandenbussche et al. (2006) and Aghion et al. (2009) combined the two above ideas, and suggested that the contribution of skilled vs unskilled labour to efficiency should depend on countries' distance/proximity to the technological frontier. They predicted that highly-educated labour would be particularly efficiency-growth enhancing close to that frontier, under the assumption that (i) at the frontier or close to it innovation matters more than adoption/replication (Acemoglu et al. 2006) (ii) innovation is a relatively more skill-intensive activity than adoption/replication (Nelson and Phelps, 1966) and (iii) that these skills are typically those people acquire within tertiary education, in particular the most advanced forms of tertiary education (master's degree...). Vandenbusshe/Aghion and their co-authors subsequently published OECD (Vandenbussche et al. 2006) — and US state-level (Aghion et al. 2009) empirical evidence in support of this assumption.

The key purpose of this paper is to use firm-level data to revisit and improve the analysis of the advanced-education/proximity-to-frontier complementarity assumption. As far as we know, this is something that has almost never been done before. One exception is the paper by Bartelsman et al. (2015), who use German and Dutch firmlevel data, but implement a slightly different econometric strategy than ours. Belgian data used here not only contain good-quality information about firms' stock of capital, 
total labour and its breakdown by educational attainment, they are also structured as panels, so they can be used to compute efficiency growth and explore its determinants. When exploiting firm-level data, on the condition that one takes good care of the presence of "noise", we can count on a large variation of the proximity-to-frontier. This is a plus from an econometric point of view. Also, the econometric literature on the estimation of efficiency frontiers has developed methods that are particularly suited to the analysis of firm-level data and for distinguishing efficiency performance and statistical noise. The results presented hereafter all rest on distance/proximity ${ }^{1}$-toefficiency frontier delivered by stochastic frontier methods (more on these, and their relevance in Sect. 2).

But independently of the nature and quality of the data used, this paper is based on few key economic considerations. First, the study of aggregate (i.e. country)-level performance outcomes should, whenever feasible, be linked to that of firms' performance within countries. In other words, macro (i.e. country)-level regularities should have micro/firm-level foundations (Bartelsman et al. 2015; Andrews et al. 2015). In modern economies, where most people work inside firms efficiency gains cannot possibly exist at a more aggregate level (i.e. countries or states) if they do not show up inside firms. And the same argument can be used about their determinants. In particular, if across countries that differ technologically, different types of human capital play different roles in both imitation/adoption and innovation activities, then that distinction should also show up when considering heterogenous firms inside a given country. Second, the existing empirical literature on the role of frontier (and education) in fostering convergence tends to overlook the important heterogeneity that exists locally (i.e. within a given country). The complexity of the technology used across firms varies a lot, even when these are located very close to each other or belong to the same industry. In other words, within countries - and perhaps also within industries in these countries-firms differ considerably as to their distance to the efficiency frontier. Very traditional and simple forms of production cohabit with top-notch, innovation-driven activities. Studies, exploiting country-specific firms micro data have documented, virtually without exception, enormous and persistent measured efficiency performance differences (Syverson 2011). The magnitudes involved are striking. Syverson reports that for the USA, within four-digit SIC industries in the manufacturing sector, the average difference in logged total factor productivity (TFP) between an industry's 90th and 10th percentile plants is 0.651 . This corresponds to a TFP ratio [that will turn out to correspond to distance/proximity to frontier hereafter] of $\mathrm{e}^{0.651}=1.92$.

The main result of the paper is that of robust econometric evidence in support of the idea that skilled workers contribute more to efficiency gains when they work inside "frontier" firms. Their contribution to efficiency growth among "laggards" is much smaller. We are also able to show the complementarity between proximity-to-frontier (PTF) and education is stronger when the latter corresponds to master's-educated workers compared to bachelor's- or upper-secondary-educated ones. Also, these results are in line with those of Bartelsman et al. (2015) who focused on German and Dutch firmlevel evidence, and used quantile regression techniques. The tentative conclusion is that akin frontier countries, firms approaching the frontier inside advanced economies

\footnotetext{
${ }^{1}$ A natural (inverse) proxy for distance to frontier is "proximity to frontier".
} 
like Belgium, depend on advanced forms of education to achieve efficiency gains; presumably because these gains require more than imitation or replication.

The rest of the paper is organized as follows. In Sect. 2, we expose our methodological choices regarding the estimation of distance/proximity-to-frontier (Stage 1) and its subsequent use to assess the role of education (i.e. Stage 2). That section also spells out our Stage- 2 econometric models. Results of Stage 1 and other data used in Stage2 analysis are presented in Sect. 3. Section 4 contains the Stage-2 key econometric results, while Sect. 5 concludes.

\section{Methodology}

\subsection{Overall Presentation}

In Stage 1, we estimate each firm's distance/proximity to the efficiency frontier using stochastic frontier methods (SF hereafter) (Aigner et al. 1977; Meeusen and van den Broeck 1977). These are methods estimating production frontier $y_{i t}=\ln f\left(K_{i t}, L_{i t}\right)+\varepsilon_{i t}$ parametrically. Specifications for $f\left(K_{i t}, L_{i t}\right)$ can vary (more on this below). The real interest lies in the fact SF takes into account potential measurement errors and other sources of statistical noise. Efficiency is no longer associated to the full Solow residual $\varepsilon_{i t}$ but only part of it. SF posit the existence of two terms: a symmetric random error term $v_{i}$ and an (in)efficiency term $\mu_{i t} \geq 0$. In other words, $y_{i t}=\ln f\left(K_{i t}, L_{i t}\right)+v_{i t}-\mu_{i t}$. The frontier is called "stochastic" because output values are bounded from above by the stochastic (i.e. random) variable $\ln f\left(K_{i t}, L_{i t}\right)+v_{i t}$. Much of the stochastic frontier analysis is directed towards the prediction of the (in)efficiency term $\mu_{i t}$. Note that our interest for SF also derives from the fact that — unlike (Vandenbussche et al. 2006; Aghion et al. 2009) — the data we use are much more disaggregated; they consist of firm-level records. And these are known for being particularly prone to measurement errors/reporting inconsistencies. In short, resorting to SF might be the right thing to do to generate realistic estimates of firms' true distance (proximity) to the (in)efficiency to frontier.

At Stage 2 these estimates, in combination with data on firms' workforce educational attainment, are used to assess education's contribution to efficiency growth (i.e. the propensity of firms to get closer to the frontier over time). And the key assumption we want to be tested is whether education's contribution depends on the distance/proximity to the frontier. This framework extends and improves the one developed by Vandenbussche et al. (2006); the main difference being that it is applied to firm-level data with (i) a lot more dispersion in terms of distance/proximity to frontier than with country-level comparisons and (ii) a more detailed description of the educational attainment of the workforce (more on this in Sect. 3).

The paper also pays attention to the risk of reverse causality/simultaneity-a form of endogeneity-when generating stage 2 results (more on this in Sect. 3). This amounts to assuming that $\mu_{i t}$ are partially anticipated by firms and influence labour input decisions, in particular their educational mix. For instance, firms experiencing positive efficiency developments, may respond by expanding their pool of educated workers. On the other hand, negative developments could lead to recruitment freeze and a 
reduction of the share of educated workers. This could cause Stage 2 OLS estimates to exaggerate the true contribution of education to efficiency gains. Various methods have been proposed to tackle that endogeneity problem. Most rest on the exploitation of the panel dimension of data. It is possible to group them in two families: instrumental Variables (IV) and Control Function (CF). In this paper, we implement both. IV methods are well known, and basically consist of instrumenting endogenous variables (i.e. education shares) with their lagged values, on the assumption that these are less likely to be correlated with the efficiency developments. CF is less commonly used. Here, we implement the Ackerberg et al. (2015) version of CF which, at its core, is a method consisting of using the consumption of various intermediates (electricity, supply and services) to proxy unobserved efficiency developments. Finally, our paper also differs from the only other paper exploring the role of education and the distance to the efficiency frontier using firm-level evidence (Bartelsman et al. 2015). That paper adopts a quantile regression strategy to capture the potentially heterogeneous contribution of education to productivity, ${ }^{2}$ while we use a two-stage approach, with an independent measure of distance/proximity to frontier.

\subsection{Stage 1: Estimating Each Firms' Proximity to the Efficiency Frontier Using Stochastic Frontier Methods}

While Vandenbussche et al. (2006) use off-the-shelf estimates of the USA's TFP level as the efficiency frontier - and each country's ratio vis-à-vis the USA as an estimate of the distance/proximity to frontier-we resort to econometric estimates derived from the analysis of firm-level data. What is more, the method we use to estimate firm-level proximity to frontier (PTF hereafter) stems from the stochastic production frontier (SF) literature. That choice is to a large extent justified by one of the weaknesses of firm-level data in comparison with country-level data: the presence of noise and measurement error. To large extent, Aigner et al. (1977) and Meeusen and van den Broeck (1977) pioneered the idea of SF models with that issue in mind. For long econometricians had been estimating average production functions. Aigner et al. wanted to reconcile econometrics with the more theoretical definition of a firm-level production function; i.e. the maximal output that can be achieve given input bundles and fixed technology. They posited that production (or the way it is measured by economists) is (i) subject to random shocks $v_{i t}$ : weather, unpredictable variations in machine or labour performance, or measurement errors; and these shocks should not be confounded with (ii) inefficiency $\mu_{i t}$ : the result of factor under the firm's control, such as technical and economic inefficiency, the will or effort of the producer and his employees. In a world without shocks/errors or inefficiencies, the firm $i$ in period $t$ in possession of capital and labour inputs $K_{i t}, L_{i t}$ would produce $f\left(K_{i t}, L_{i t}\right)$. But more realistically, output is affected by both and writes $Y_{i t}=f\left(K_{i t}, L_{i t}\right) e^{v_{i t}-\mu_{i t}}$ or in logs

$$
\ln Y_{i t}=\ln f\left(K_{i t}, L_{i t}\right)+v_{i t}-\mu_{i t}
$$

\footnotetext{
2 In the Bartelsman et al. (2015) study, the th quantile return to educated labour corresponds to the marginal change in productivity due to a marginal change in the share of that type of workers conditional on being in a firm belonging to the th quantile of the overall outcome distribution (i.e. the outcome being labour productivity in their case).
} 
where $\mu_{i t} \geq 0$ represents the firms' technical inefficiency/distance to the frontier. Equivalently, if [as done in the rest of the paper] one rather considers a firm's efficiency/proximity to the frontier, the equation writes

$$
\ln Y_{i t}=\ln f\left(K_{i t}, L_{i t}\right)+v_{i t}+\ln P T F_{i t}
$$

where $\ln P T F_{i t}$ with $\ln P T F_{i t} \leq 0$ and $P T F_{i t} \equiv e^{-\mu_{i t}} ; 0 \leq P T F_{i t} \leq 1$ is the ratio of observed output to the corresponding stochastic frontier output: $P T F_{i t}=$ $Y_{i t} / f\left(K_{i t}, L_{i t}\right) e^{v_{i t}}$. If proximity(distance) is maximal(minimal) $P T F_{i t}=1 ; \mu_{i t}=0$, the firm is achieving the optimal output with the technology embodied in the production function $f\left(K_{i t}, L_{i t}\right) e^{v_{i t}}$. Andrews et al. (2015) would call it a "frontier" firm. When $P T F_{i t}<1 ; \mu_{i t} \geq 0$, the firm is not making the most of the inputs $K, L$ and proximity (distance) to frontier falls(rises). Andrews et al. (2015) would refer to such a firm as being a "laggard".

Of course, estimation is complicated by the presence of two error terms in (1). The "noise" term $v_{i t}$, is assumed to be randomly normally [symmetric] distributed $N\left(0, \sigma_{\nu}\right)$, while the $\mu_{i t}$ term is assumed half-normally [asymmetrically] $N^{+}\left(0, \sigma_{\mu}\right)$ distributed. For the sum of a symmetric normal random variable and a truncated normal random variable [dropping $t$ ], the log-likelihood function is

$$
\ln L=\sum_{i=1}^{N}\left\{1 / \ln (2 / \pi)-\ln \left(\sigma_{S}\right)+\ln \Phi\left(-\varepsilon_{i} \lambda / \sigma_{S}\right)-\varepsilon_{i}^{2} 2 \sigma_{S}^{2}\right\}
$$

where $\varepsilon_{i}=v_{i}-\mu_{i}=\ln Y_{i}-\ln f\left(K_{i}, L_{i}\right) ; \sigma_{S}=\sigma_{\mu}+\sigma_{v} ; \lambda=\sigma_{\mu} / \sigma_{v}$ and $\Phi()$ is the cumulative distribution function of the normal distribution.

To obtain estimation for $\mu_{i}$ one can use the mean of the conditional distribution $f\left(\mu_{i} \mid \varepsilon_{i}\right)$

$$
E\left(\mu_{i} \mid \varepsilon_{i}\right)=\mu_{i}^{*}+\sigma^{*}\left\{\phi\left(-\mu_{i}^{*} / \sigma^{*}\right) / \Phi\left(\mu_{i}^{*} / \sigma^{*}\right)\right\}
$$

Then the proximity to frontier will be estimated by

$$
\widehat{P T F}=E\left(e^{-u i} \mid \varepsilon_{i}\right)=\left\{\left[1-\Phi\left(\sigma^{*}-\mu_{i}^{*} / \sigma^{*}\right)\right] /\left[1-\Phi\left(-\mu_{i}^{*} / \sigma^{*}\right)\right]\right\} e^{\mu_{i}^{*}+.5 \sigma^{* 2}}
$$

where $\mu_{i}^{*}=-\varepsilon_{i} \sigma_{\mu}^{2} / \sigma_{v}^{2}=-\varepsilon_{i} \lambda^{2} ; \sigma^{*}=\sigma_{\mu} \sigma_{v} / \sigma_{S}$

Estimated parameter $\lambda$ in the above likelihood expression is convenient because it is an indicator of the relative variability of the two sources of random error that distinguish firms from one another. In particular $\lambda^{2}=0$ implies $\sigma_{\mu}^{2}=0$ and/or $\sigma_{v}^{2}=\infty$ i.e. that the symmetric term (random shocks/measurement errors) dominates in the determination of $\varepsilon_{\mathrm{i}}$. In Eq. (5), $\mu_{i}^{*}=0$ and $\sigma^{*}=0$ which lead to $\widehat{P T F}=1$ (i.e. maximal proximity/efficiency). 
Turning to the econometric version of model (2), we have

$$
\ln Y^{j}=\ln f\left(K_{i t}^{j}, L_{i t}^{j}\right)+\Psi_{i t}^{j}+\ln P T F_{i t}^{j}+v_{i t}^{j}
$$

note the addition of a vector of year fixed effects $\Psi$ i.e. year-to-year shifts of the frontier capturing the existence of technological progress, as it is commonly done in the SF literature. More significantly, note also that we allow for the model to be specific to the sector/industry $j$ to which the firm belongs. In practice, this means that Stage 1 analysis is carried out sector by sector.

Finally, there is that $f\left(K_{i t}^{j}, L_{i t}^{j}\right)$ can be specified in various ways. Hereafter, we will speficied it as a Cobb-Douglas, or-to relax the parametric restrictions inherent to the latter-as a Translog. ${ }^{3}$

\subsection{Stage 2: Analysing the Determinants of Efficiency Growth}

Stage 2 focuses on the propensity of firms to become more effective over time in the sense that they get closer to the Stage-1-estimated frontier. Our focus is not productivity growth, but only on one of its components. Productivity growth is combined effect of (i) a shift of the frontier (technical change). and (ii) a movement of the economy towards the frontier (efficiency growth). What is more, our aim is to assess the role of the educational attainment of the workforce in achieving these efficiency gains, and more specifically the extent to which that contribution depends on the initial distance/proximity to that frontier. The model we estimate generalises the one used by Vandenbussche et al. (2006) and Aghion et al. (2009)

$$
\begin{array}{r}
y_{i t} \equiv \widehat{p t f}_{i t}-\widehat{p t f}_{i t-1}=\alpha+\beta_{i t-1} \widehat{p t f}_{i t-1}+\gamma_{1} S E C_{i t-1}+\gamma_{2} B A C H_{i t-1}+\gamma_{3} M A S T_{i t-1} \\
+\eta_{1} S E C_{i t-1} \widehat{p t f}_{i t-1}+\eta_{2} B A C H_{i t-1} \widehat{p t f}_{i t-1}+\eta_{3} M A S T_{i t-1} \widehat{p t f}_{i t-1}+\theta F_{i t}+\varepsilon_{i t}
\end{array}
$$

The efficiency growth achieved by firm $i$ between period $t$ and $t-1$ is the change in the proximity to frontier i.e. $y_{i t} \equiv \widehat{p t f}_{i t}-\widehat{p t f}_{i t-1}$; with $\widehat{p t f}_{i t} \equiv \ln \widehat{P T F}_{i t-1}$. The initial shares of the workers with, a secondary, bachelor's and master's attainment are, respectively $S E C_{i t-1} ; B A C H_{i t-t} ; M A S T_{i t-1}$ with the least educated workers being the reference (more on the definition of education below). The (initial) (log of) the proximity to the frontier is $\widehat{p t f}_{i t-1}$. The main variables of interest are the education shares interacted with the (log of) proximity to frontier $\widehat{p t f}_{i t-1}$. The sign of their coefficients

\footnotetext{
3 The Translog is know for being a flexible functional form for production functions. One of its main advantages is that, unlike the Cobb-Douglas, it does not assume rigid premises such as unitary elasticity of substitution or constant returns to scale. Also Translog functions have been shown to be second-order Taylor approximations of any technology (Fuss et al. 1978; Chambers 1988).
} 
$\eta$ 's provide a direct test of the Vandenbussche/Aghion et al. assumption. Positive and statistically significant $\eta$ 's will be interpreted as evidence that better-educated labour has a larger efficiency growth-enhancing effect closer to the technological frontier. Note that $p t f_{i t-1}$ is a negative number (i.e. $\log$ of a ratio $<1$ ) with a maximum of 0 . That means that coefficients $\gamma$ 's capture education's contribution at the frontier. Compare to Vandenbussche/Aghion, the main advantage of the above model is that it reflects the heterogeneity of educational attainment and allows for (i) variable contribution of education to efficiency growth and (ii) variable interaction with the proximity to frontier. When estimating (7), one can thus assess whether the efficiency growth enhancing effect closer to the efficiency frontier is larger for, say, master's-educated workers compared to bachelor's-educated workers or secondary-educated workers. Vector $F_{i t}$ represents the list of control variables. There will be more on this in Sect. 3. But note already that it systematically comprises industry ${ }^{4} / y e a r$ fixed effects (that among other things control for output price inflation differences), plus the annual change of the share of workers by educational attainment $\left(\triangle S E C_{i t} ; \triangle B A C H_{i t} ; \triangle M A S T i_{t}\right)$. Why distinguishing the contribution of $t-l$ stock of education from it short-term variation? Fundamentally, for the same reason that led Vandenbussche/Aghion to retain educational attainment in $t-1$ and not in $t$ as a predictor of $t-1$ to $t$ efficiency growth: the problem of reverse causality/simultaneity. Educational attainment in $t$ (or the variation of educational attainment between $t-1$ and $t$ ) may be-at least partially-caused by firms' efficiency gains rather than the opposite. In econometrics this problem is refered to as simultaneity bias or reverse causality. To limit that risk, the strategy is to prioritise $t-1$ values of educational attainment (or further lags-more on this when we will implement IV of Control function estimation of 7) as (causal) explanation of firm-level efficiency growth).

\section{Data Description and Stage-1 Results}

Our data come from the Bel-first database. We have extracted a large (unbalanced) panel of 261,935 firm-year observations corresponding to the situation of 39,901 firms, from all industries forming the Belgian private economy (to the exclusion of mining and agriculture), in the period 2008-2014 (6 consecutive years). Contrary to many studies thus, we do no restrict the analysis to the manufacturing sector. Our firms are largely documented in terms of output (value added), capital used, sums dedicated to the purchase of intermediates and services, ${ }^{5}$ and total numbers of hours worked, with a breakdown by educational attainment. As to capital-in part because we cover a lot of non-manufacturing industries - we use the most encompassing estimate available in the dataset (i.e. total assets). The latter comprises a firm's current (receivables and stocks) and non-currents assets (both non-financials and financials). Regarding human capital, it is worth stressing that Bel-first contains the breakdown of the total workforce - and this is a relatively unique feature for firm-level data-into 4 levels of educational attainment; (1) at most a primary education attainment, (2) at most upper-

\footnotetext{
4 NAICS 2-digit.

5 That are necessary to implement the Ackerberg et al. (2015) control/proxy econometric estimation aimed at controling for the risk of reverse causality/simultaneity.
} 
Table 1 Descriptive statisticspercentiles of main regressors used to estimate proximity to frontier (PTF) (Stage-1 equation). Source: Own calculations using Belfirst 2008-2014

\begin{tabular}{lll}
\hline & $\begin{array}{l}\text { Percentile of number } \\
\text { of workers in } \\
\text { full-time equivalent }\end{array}$ & $\begin{array}{l}\text { Total capital [per } \\
\text { employee] in th. } \\
\text { EUR }\end{array}$ \\
\hline p5 & 6.00 & 39 \\
p25 & 16.00 & 117 \\
p50 & 34.00 & 225 \\
p75 & 74.00 & 508 \\
p95 & 325.00 & 4102 \\
$N$ & 39,901 & \\
\hline
\end{tabular}

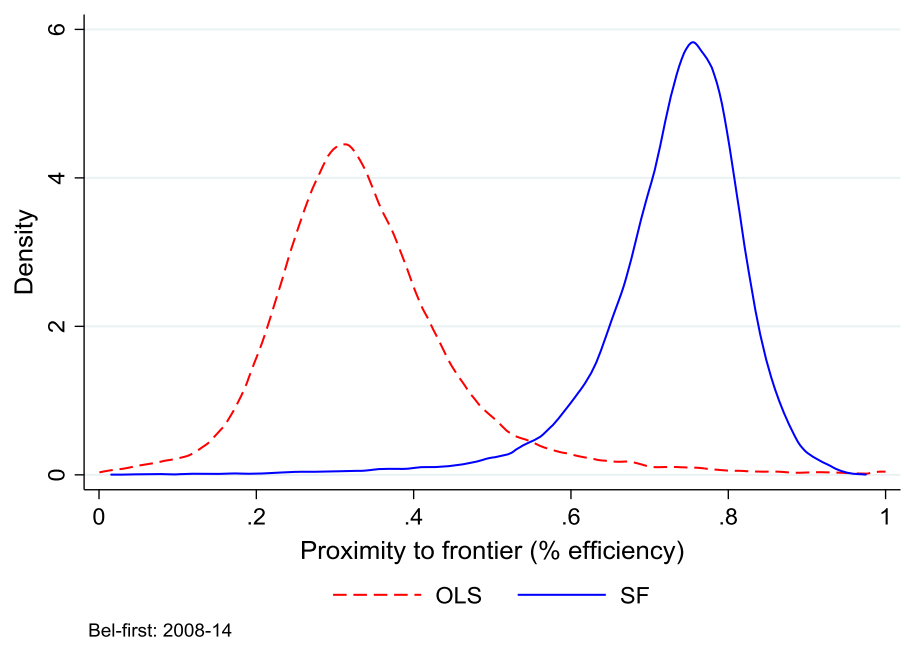

Fig. 1 Stochastic FROntier(SF)- versus OLS-estimated proximity to frontier(PTF). Comparison of density distributions. Year 2014. Source: Own calculations using Belfirst 2008-2014. The STATA frontier command was use to generate the SF-estimated values for the proximity to frontier

secondary education attainment, (3) with a 2 to 3-year college attainment (bachelor's degrees hereafter), and (4) 5-year university attainment (master's hereafter).

Table 1 reports moments (p25, p50/median, p75) of the distribution of the input variables (labour and capital) used at Stage 1. Figure 1 reports Stage 1-estimated PTFs computed with SF vs OLS/Solow-residuals. Its sole purpose is to illustrate how much SF makes a difference in estimating PTF. On display are the distributions obtained when using the Cobb-Douglas specification (all sectors/industries pooled). The shift to the right with SF (firms appear much closer to the frontier) is the direct consequence of allowing the frontier to be stochastic i.e. to comprise a purely random term $v_{i t}$. Figure 2 also displays the distribution of PTF when estimation is carried out industry by industry ${ }^{6}$ (as is the case for all the results presented hereafter). Quite logically, the latter distribution shifts further to the right, as many firms tend to be closer to the industry frontier (the one characterizing their industry) than to the national frontier.

\footnotetext{
6 NAICS 2 digits.
} 


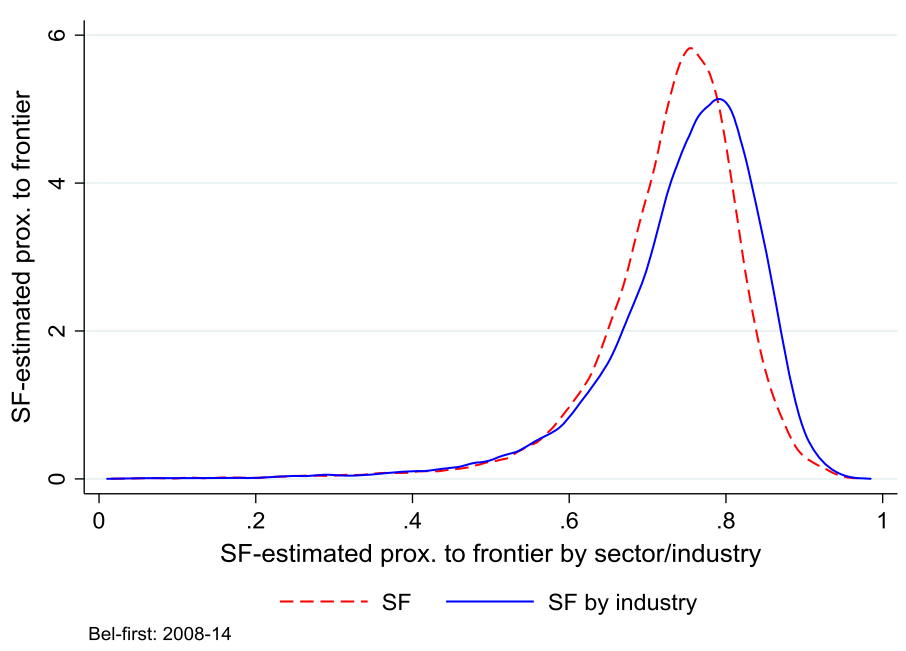

Fig. 2 SF-estimated proximity to frontier (PTF). Polled vs industry by industry sample-scatter plot. Year 2014. Source: own calculations using Belfirst 2008-2014. The STATA frontier command was use to generate the SF-estimated values for the proximity to frontier

Tables 2, 3 and 4 describe the key variables used at Stage 2, where we estimate equation (7). First, the moments (p25, p50/median, p75) of the dependant variable: i.e. the proximity-to-frontier growth (PTF) rate, reflecting the propensity of firms to become more effective over time. Table 2 reports the annual growth rates, whereas Table 3 the 6-year equivalent. At Stage 2, we lose one period (i.e. 2008) as the dependent variable is the annual PTF growth rate (Table 2). And that we just keep one period when we use the 6-year growth rate as dependent variable (Table 3). Table 4 describes the main Stage- 2 explanatory variables. It shows that secondary-educated workers represent about $59 \%$ of the total workforce, while bachelor's-educated and master's-educated workers count for about 13.5 and $5 \%$ of the total respectively. Note, in Table 4's last column, the information about the age of firms (i.e.\# years elapsed since incorporation) that is in our list of controls, alongside industry (NAICS 2 digits) interacted with year, and the province where the firm is located. The age of firm might be an important determinant of efficiency growth (our key dependent variable) and, at the same time, be correlated with that education structure of the workforce. It may be also indirectly control for the age of the workforce (unobserved in our data), and the latter's impact on efficiency growth. It is indeed well established-both internationally (Ouimet and Zarutskie 2014) and in Belgium (Dumont and Kegeles 2016), - that younger workers and overrepresented in younger firms. As to the provinces, Belgium counts 11 of them. These are 50-80 kilometre-wide administrative boundaries, each located in one of the country's 3 regions (French-Speaking Wallonia, Flemish-Speaking Flanders, and bilingual Brussels). We use province fixed effects to capture location-based determinants of efficiency growth (presence of a large city, density of infrastructure...) highlighted by economic geography, but also-something that might be important in the Belgian context - those that may stem for regional heterogeneity. 


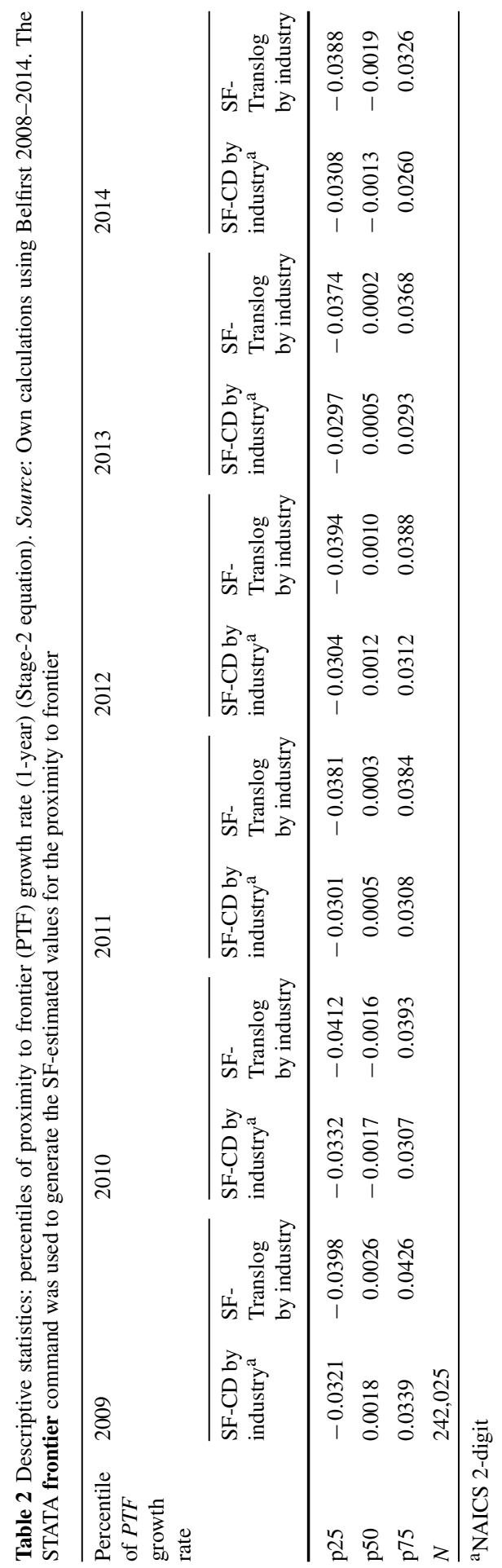


Table 3 Descriptive statistics: percentiles of proximity to frontier (PTF) growth rate (6-year) (Stage-2 equation). Source: Own calculations using Belfirst 2008-2014. The STATA frontier command was used to generate the SF-estimated values for the proximity to frontier

${ }^{a}$ NAICS 2-digit

\begin{tabular}{lll}
\hline $\begin{array}{l}\text { Percentile of } P T F \\
\text { growth rate }\end{array}$ & 2014 & \\
\cline { 2 - 3 } & $\begin{array}{l}\text { SF-Cobb-Douglas } \\
\text { frontier, by industry }\end{array}$ & $\begin{array}{l}\text { SF-Translog frontier, } \\
\text { by industry }\end{array}$ \\
\hline p25 & -0.0538 & -0.0667 \\
p50 & 0.0007 & 0.0006 \\
p75 & 0.0530 & 0.0669 \\
$N$ & 39,901 & \\
\hline
\end{tabular}

\section{Stage-2 Econometric Results}

\subsection{Main Results}

Table 5 and Fig. 3 present a first series of Stage- 2 results, corresponding to the estimation of Eq. (7). They are divided in four parts corresponding to the Cobb-Douglas and Translog specifications of the SF-estimated efficiency frontier; when the model is estimated using an industry-by-industry frontier. ${ }^{7}$ In all cases, the key coefficient corresponds to the education $\mathrm{x} P T F$ interaction variable $(\eta$ ' $s)$. If it is true that educated labour has a higher efficiency growth-enhancing effect closer to the technological frontier, then the estimated coefficient for that variable should be positive and statistically significant. We verify this, but with strong evidence [e.g. col. 2 of Table 5, or Fig. 3] that complementarity with PTF is significantly stronger for master's-educated workers $\left(\eta^{\text {mast }}=0.162\right.$ for th Cobb-Douglas specification, 0.177 for the Translog) compared to bachelor's-educated or secondary-educated workers for which we have coefficient ranging from 0 to 0.048 and not always statistically significant. At the bottom of Table 5, we report the results of hypothesis test that $\eta$ 's taken pairwise are equal. While one cannot reject the possibility that $\eta^{\text {bach }}=\eta^{\text {second }}$, there is little doubt that $\eta^{\text {mast }}>\eta^{\text {bach }}$ or that $\eta^{\text {mast }}>\eta^{\text {second. }}$. These results hold whatever the way we estimate PTF (i.e. Cobb-Douglas vs Translog specification).

Remember that, in Table 5, reported coefficients for the education attainment inform about the latter's contribution to productivity growth at the frontier. ${ }^{8} \mathrm{~A} .079$ value thus suggests that a $0-100 \%$ rise of the share of master's-educated workers in those firms leads to a 7.9\%-point rise of the annual efficiency growth rate. More realistically, a $10 \%$-point rise of the share of master's-educated workers inside frontier firms adds $0.79 \%$-point to that rate.

The other variables present is the model have the expected sign. The closer firms initially (i.e. in $t-1$ ) are to the frontier the lower their efficiency growth during the subsequent period. This is supportive of the standard idea of convergence over time: firms with lower efficiency levels (the "laggards") tend to catch up with the frontier firms, via dissemination or imitation of technological or managerial best practices.

\footnotetext{
7 NAICS 2 digits.

8 The $\log$ of proximity-to-frontier being negative $\left(-\infty \leq \ln P T F_{i t} \leq 0\right)$ the positive $\eta$ 's mean that we get smaller contribution to annual efficiency gains when distance to frontier rises (proximity to frontier falls).
} 


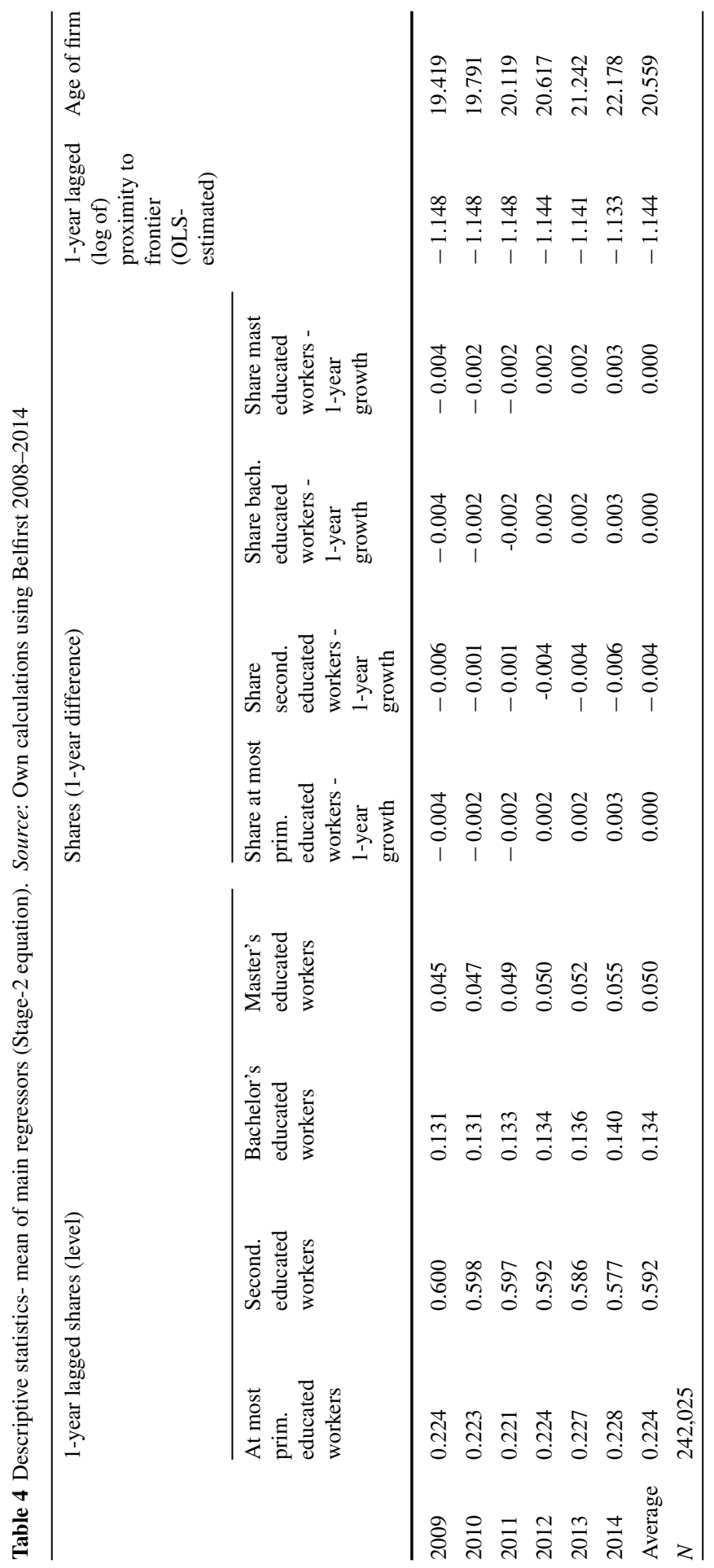


Table 5 The contribution to 1-year efficiency growth ${ }^{\mathrm{a}}$ of educated workers, according to the proximity to

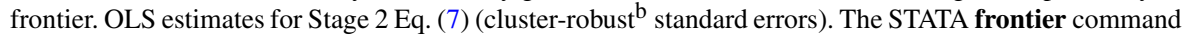
was use to generate the SF-estimated values for the proximity to frontier

\begin{tabular}{|c|c|c|}
\hline & Cobb-Douglas SF-by industry ${ }^{c}$ & Translog SF-by industry ${ }^{\mathrm{c}}$ \\
\hline$\widehat{p t f}_{i t-1}$ & $\begin{array}{l}-0.451 * * * \\
(0.017)\end{array}$ & $\begin{array}{l}-0.476^{* * * *} \\
(0.018)\end{array}$ \\
\hline$S E C_{i t-1}$ & $\begin{array}{l}0.007 \\
(0.005)\end{array}$ & $\begin{array}{l}0.011 \\
(0.006)\end{array}$ \\
\hline$B A C H_{i t-1}$ & $\begin{array}{l}0.012 \\
(0.009)\end{array}$ & $\begin{array}{l}0.030 * * \\
(0.010)\end{array}$ \\
\hline$M_{A S T} T_{i t-1}$ & $\begin{array}{l}0.079 * * * \\
(0.012)\end{array}$ & $\begin{array}{l}0.083 * * * \\
(0.013)\end{array}$ \\
\hline$\widehat{p t f}_{i t-1} . S E C_{i t-1}\left[\eta^{\sec o n d}\right]$ & $\begin{array}{l}0.032 \\
(0.019)\end{array}$ & $\begin{array}{l}0.048 * \\
(0.021)\end{array}$ \\
\hline$\widehat{p t f}_{i t-1} \cdot B A C H_{i t-1}\left[\eta^{b a c h}\right]$ & $\begin{array}{l}-0.002 \\
(0.031)\end{array}$ & $\begin{array}{l}0.051 \\
(0.031)\end{array}$ \\
\hline$\widehat{p t f}_{i t-1} \cdot M A S T_{i t-1}\left[\eta^{\text {mast }}\right]$ & $\begin{array}{l}0.162 * * * \\
(0.039)\end{array}$ & $\begin{array}{l}0.177 * * * \\
(0.039)\end{array}$ \\
\hline Controls & $\begin{array}{l}\text { yearXindustry(NAICS 2-digit), } \\
\text { province, year of incorporation, } \\
\text { change of educational mix } \\
\left(\triangle S E C_{i t} ; \triangle B A C H_{i t} ; \triangle M A S T_{i t}\right)\end{array}$ & $\begin{array}{l}\text { yearXindustry(NAICS } \\
\text { 2-digit), province, year of } \\
\text { incorporation, change of } \\
\text { educational mix }\left(\triangle S E C_{i t} \text {; }\right. \\
\left.\triangle B A C H_{i t} ; \triangle M A S T_{i t}\right)\end{array}$ \\
\hline Nobs (firmsXyear) & 242,025 & 242,025 \\
\hline Nfirms & 39,901 & 39,901 \\
\hline $\mathrm{R}^{2}$ & 0.2254 & 0.2311 \\
\hline $\operatorname{prob} \eta^{\text {mast }}=\eta^{\text {bach }}$ & 0.0006 & 0.0065 \\
\hline prob $\eta^{\text {mast }}=\eta^{\text {second }}$ & 0.0004 & 0.0004 \\
\hline prob $\eta^{\text {bach }}=\eta^{\text {second }}$ & 0.2303 & 0.9322 \\
\hline
\end{tabular}

Estimates obtained using Bel-first firm-level data (2008-2014)

$* p<0.05 ; * * p<0.01 ; * * * p<0.001$

$\widehat{a}_{p t f}$ it $-\widehat{p t f}_{i t-1}$

${ }^{\mathrm{b}}$ Standard errors are computed to account for firm-level clustering (correlation of error terms)

${ }^{\mathrm{c}}$ NAICS 2-digit

\subsection{Robustness Checks}

We checked the robustness of our empirical results in two directions. First, we use 6year efficiency growth instead of 1-year growth. Results are reported in Table 6 and are qualitatively very similar to those on display in Table 5 . Second, and more significantly, we address the problem of reverse causality/simultaneity bias. To that end, we first estimate the relevant parameters of our model using only "internal" instruments and the generalize method of moments (IV-GMM here after). The essence of this strategy is to use lagged values of endogenous variables (here lags 1-3) as instruments for the endogenous variables. An alternative to IV-GMM that seems promising and relevant is 

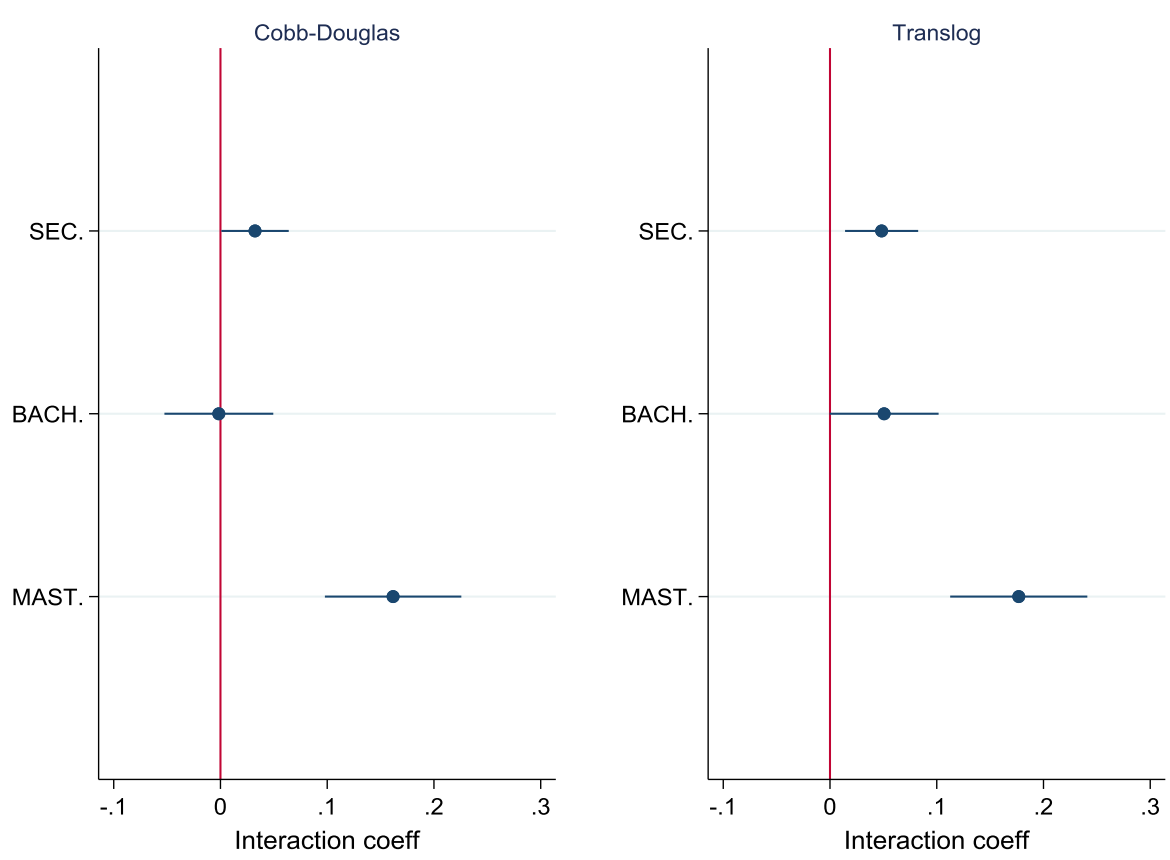

Fig. 3 The contribution to 1-year efficiency growth ${ }^{\mathrm{a}}$ of educated workers, according to the proximity to frontier-plot of the interaction education-proximity-to-frontier OLS-estimated coefficients Eq. (7). SF estimates (cluster-robust ${ }^{\mathrm{b}}$ standard errors). Estimates obtained using Bel-first firm-level data (2008-2014) $\widehat{a}_{p t f} i t-\widehat{p t f}_{i t-1}$. The STATA frontier command was use to generate the SF-estimated values for the proximity to frontier

${ }^{\mathrm{b}}$ Standard errors are computed to account for firm-level clustering (correlating of error terms)

to adopt the more structural approach initiated by Olley and Pakes (1998) and further developed by Ackerberg et al. (2015) (ACF-GMM, hereby). The essence of these approaches is to use some function of a firm's consumption of intermediates to control for (proxy) time-varying efficiency developments that are (partially) anticipated by the firms and correlated with the observed level of education (see Appendix for a full exposition of the ACF 2 steps estimator).

Results for IV-GMM are reported in Table 7 . We reproduce the key results of Table 5, namely that of strong and statistically significant complementarity with PTF for master's-educated workers $\left(\eta^{\text {mast }}=0.149\right.$ for th Cobb-Douglas specification, 0.181 for the Translog) compared to bachelor's-educated or secondary-educated workers for which we have coefficient ranging from 0 to 0.096 but not statistically significant. At the bottom of Table 7, we report the results of hypothesis test that $\eta$ 's taken pairwise are equal. And again, there is little doubt that $\eta^{\text {mast }}>\eta^{\text {second. }}$. That $\eta^{\text {mast }}>\eta^{\text {bach }}$ or $\eta^{\text {bach }}>\eta^{\text {sec }}$ is less clear cut. Note that the bottom of Table 7 reports that usual statistics assessing the relevance of our IV-GMM estimator.

The first test determines whether endogenous regressors in the model are in fact exogenous. Reported GMM-C statistics is high and statistically different than zero, meaning that there are good reasons to believe that our regressors are endogenous and that IV-GMM should be preferred to OLS. Next, we have statistics that measure 
Table 6 The contribution to 6-year efficiency growth ${ }^{\mathrm{a}}$ of educated workers, according to the proximity to frontier. OLS estimates for Stage $2 \mathrm{Eq}$. (7) (cluster-robust ${ }^{\mathrm{b}}$ standard errors). The STATA frontier command was used to generate the SF-estimated values for the proximity to frontier

\begin{tabular}{|c|c|c|}
\hline & Cobb-Douglas SF-by industry ${ }^{\mathrm{c}}$ & Translog SF-by industry \\
\hline$\widehat{p t f}_{i t-1}$ & $\begin{array}{l}-0.697^{* * *} \\
(0.0098)\end{array}$ & $\begin{array}{l}-0.724^{* * *} \\
(0.0097)\end{array}$ \\
\hline$S E C_{i t-1}$ & $\begin{array}{l}-0.004 \\
(0.0026)\end{array}$ & $\begin{array}{l}-0.007^{*} \\
(0.0032)\end{array}$ \\
\hline$B A C H_{i t-1}$ & $\begin{array}{l}0.019^{* * * *} \\
(0.0042)\end{array}$ & $\begin{array}{l}0.018^{* * * *} \\
(0.0052)\end{array}$ \\
\hline$M_{A S T} T_{i t-1}$ & $\begin{array}{l}0.045^{* * *} \\
(0.0069)\end{array}$ & $\begin{array}{l}0.042^{* * *} \\
(0.0085)\end{array}$ \\
\hline$\widehat{p t f}_{i t-1} . S E C_{i t-1}\left[\eta^{\sec o n d}\right]$ & $\begin{array}{l}-0.005 \\
(0.0043)\end{array}$ & $\begin{array}{l}-0.006 \\
(0.0049)\end{array}$ \\
\hline$\widehat{p t f}_{i t-1} \cdot B A C H_{i t-1}\left[\eta^{b a c h}\right]$ & $\begin{array}{l}0.006 \\
(0.0066)\end{array}$ & $\begin{array}{l}0.030^{* * * *} \\
(0.0077)\end{array}$ \\
\hline$\widehat{p t f}_{i t-1} \cdot M A S T_{i t-1}\left[\eta^{\text {mast }}\right]$ & $\begin{array}{l}0.103^{* * *} \\
(0.0091)\end{array}$ & $\begin{array}{l}0.115^{* * *} \\
(0.0108)\end{array}$ \\
\hline Controls & $\begin{array}{l}\text { yearXindustry(NAICS 2-digit), } \\
\text { province, year of incorporation, } \\
\text { change of educational mix } \\
\left(\triangle S E C_{i t} ; \triangle B A C H_{i t} ; \triangle M A S T \cdot{ }_{\cdot i t}\right)\end{array}$ & $\begin{array}{l}\text { yearXindustry(NAICS } \\
\text { 2-digit), province, year of } \\
\text { incorporation, change of } \\
\text { educational mix }\left(\triangle S E C_{i t} \text {, }\right. \\
\left.\triangle B A C H_{i t} ; \triangle M A S T_{i t}\right)\end{array}$ \\
\hline Nobs (firmsXyear) & 39,901 & 39,901 \\
\hline Nfirms & 39,901 & 39,901 \\
\hline $\mathrm{R}^{2}$ & 0.44 & 0.44 \\
\hline $\operatorname{prob} \eta^{\text {mast }}=\eta^{\text {bach }}$ & 0.0000 & 0.0000 \\
\hline prob $\eta^{\text {mast }}=\eta^{\text {second }}$ & 0.0000 & 0.0000 \\
\hline prob $\eta^{\text {bach }}=\eta^{\text {second }}$ & 0.0086 & 0.0557 \\
\hline
\end{tabular}

Estimates obtained using Bel-first firm-level data (2008-2014)

$* p<0.05 ; * * p<0.01 ; * * * p<0.001$

$\widehat{a}_{p t f}-\widehat{p t f}_{i t-6}$

${ }^{\mathrm{b}}$ Standard errors are computed to account for firm-level clustering (correlation of error terms)

${ }^{\mathrm{c}}$ NAICS 2-digit

the relevance of our instruments. For them to be a valid, they must be sufficiently correlated with the included endogenous regressors. Moreover, what really matters with IV estimation is whether the component of a regressor that is orthogonal to the other regressors can be explained by the component of the predicted value of that regressor that is orthogonal to the predicted values of the other regressors in the model. Shea's partial $\mathrm{R}^{2}$ statistic measures this correlation. Because the bias of instrumental-variables estimators increases as more instruments are used, we report Shea's adjusted partial $\mathrm{R}^{2}$ statistics, as they make a degrees-of-freedom adjustment for the number of instruments, analogous to the adjusted $\mathrm{R}^{2}$ measure used in OLS regression. Although what constitutes a "low" value for Shea's partial $\mathrm{R}^{2}$ depends 
Table 7 The contribution to 1-year efficiency growth ${ }^{\mathrm{a}}$ of educated workers, according to the proximity to frontier. IV-GMM estimates for Stage 2 Eq. (7) where regressors are instrumented by their lagged 1-3 values (cluster-robust ${ }^{\mathrm{b}}$ standard errors). The STATA frontier command was use to generate the SF-estimated values for the proximity to frontier

\begin{tabular}{|c|c|c|}
\hline & Cobb-Douglas SF- by industry ${ }^{c}$ & Translog SF-by industry \\
\hline$\widehat{p t f}_{i t-1}$ & $\begin{array}{l}-0.307 * * * \\
(0.0337)\end{array}$ & $\begin{array}{l}-0.340 * * * \\
(0.0394)\end{array}$ \\
\hline$S E C_{i t-1}$ & $\begin{array}{l}-0.006 \\
(0.0105)\end{array}$ & $\begin{array}{l}-0.004 \\
(0.0139)\end{array}$ \\
\hline$B A C H_{i t-1}$ & $\begin{array}{l}0.022 \\
(0.0173)\end{array}$ & $\begin{array}{l}0.043 * \\
(0.0197)\end{array}$ \\
\hline$M A S T_{i t-1}$ & $\begin{array}{l}0.068 * * * \\
(0.0204)\end{array}$ & $\begin{array}{l}0.078 * * * \\
(0.0229)\end{array}$ \\
\hline$\widehat{p t f}_{i t-1} \cdot S E C_{i t-1}\left[\eta^{\sec o n d}\right]$ & $\begin{array}{l}-0.014 \\
(0.0384)\end{array}$ & $\begin{array}{l}0.001 \\
(0.0459)\end{array}$ \\
\hline$\widehat{p t f}_{i t-1} \cdot B A C H_{i t-1}\left[\eta^{b a c h}\right]$ & $\begin{array}{l}0.037 \\
(0.0577)\end{array}$ & $\begin{array}{l}0.096 \\
(0.0620)\end{array}$ \\
\hline$\widehat{p t f}_{i t-1} \cdot M A S T_{i t-1}\left[\eta^{\text {mast }}\right]$ & $\begin{array}{l}0.149 * \\
(0.0692)\end{array}$ & $\begin{array}{l}0.181^{*} \\
(0.0741)\end{array}$ \\
\hline Controls & $\begin{array}{l}\text { yearXindustry (NAICS 2-digit), } \\
\text { province, year of incorporation, } \\
\text { change of educational mix } \\
\left(\triangle S E C \cdot{ }_{i t} ; \triangle B A C H_{i t} ; \triangle M A S T_{i t}\right)\end{array}$ & $\begin{array}{l}\text { yearXindustry (NAICS } \\
\text { 2-digit), province, year of } \\
\text { incorporation, change of } \\
\text { educational mix }\left(\triangle S E C_{i t} \text {, }\right. \\
\left.\triangle B A C H_{i t} ; \triangle M A S T_{i t}\right)\end{array}$ \\
\hline Nobs (firmsXyear) & 102,342 & 102,342 \\
\hline Nfirms & 39,902 & 39,902 \\
\hline WaldX & 1092.6365 & 1018.7167 \\
\hline $\operatorname{prob} \eta^{\text {mast }}=\eta^{\text {bach }}$ & 0.2233 & 0.3770 \\
\hline prob $\eta^{\text {mast }}=\eta^{\text {second }}$ & 0.0086 & 0.0053 \\
\hline \multicolumn{3}{|l|}{$\begin{array}{l}I V \text {-Test of endogeneity of } \\
\text { regressors }\end{array}$} \\
\hline GMM C-statistic $\chi^{2}$ & 17.6231 & 12.9878 \\
\hline prob_C-stat. $=0$ & 0.0072 & 0.0432 \\
\hline C-stat. df & 6 & 6 \\
\hline \multicolumn{3}{|l|}{$\begin{array}{l}\text { IV-First-stage assessment } \\
\left(\text { Shea's Adj. Partial } R^{2}\right)\end{array}$} \\
\hline$S E C_{i t-1}$ & .68 & .69 \\
\hline $\mathrm{BACH}_{i t-1}$ & .68 & .68 \\
\hline$M_{A S T} T_{i t-1}$ & .75 & .75 \\
\hline$\widehat{p t f}_{i t-1} . S E C_{i t-1}\left[\eta^{\sec o n d}\right]$ & .66 & .67 \\
\hline$\widehat{p t f}_{i t-1} \cdot B A C H_{i t-1}\left[\eta^{b a c h}\right]$ & .69 & .69 \\
\hline
\end{tabular}


Table 7 continued

\begin{tabular}{|c|c|c|}
\hline Controls & $\begin{array}{l}\text { yearXindustry (NAICS 2-digit), } \\
\text { province, year of incorporation, } \\
\text { change of educational mix } \\
\left(\triangle S E C_{\cdot i t} ; \triangle B A C H_{i t} ; \triangle M A S T_{i t}\right)\end{array}$ & $\begin{array}{l}\text { yearXindustry (NAICS } \\
\text { 2-digit), province, year of } \\
\text { incorporation, change of } \\
\text { educational mix }\left(\triangle S E C_{i t} \text {; }\right. \\
\left.\triangle B A C H_{i t} ; \triangle M A S T_{i t}\right)\end{array}$ \\
\hline$\widehat{p t f}_{i t-1} \cdot M A S T_{i t-1}\left[\eta^{\text {mast }}\right]$ & .77 & .77 \\
\hline \multicolumn{3}{|l|}{$\begin{array}{l}\text { Exogeneity (orthogonality of } \\
\text { instruments) }\end{array}$} \\
\hline Hansen & 7.7696 & 6.4926 \\
\hline prob Hansen $=0$ & 0.8029 & 0.8892 \\
\hline Hansen $\mathrm{df}$ & 12 & 12 \\
\hline
\end{tabular}

Estimates obtained using Bel-first firm-level data (2008-2014). All regressors with and educational content are instrumetent using lags $1-3$

$* p<0.05 ; * * p<0.01 ; * * * p<0.001$

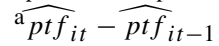

${ }^{\mathrm{b}}$ Standard errors are computed to account for firm-level clustering (correlation of error terms)

${ }^{\mathrm{c}}$ NAICS 2-digit

on the specifics of the model being fit and the data used, our results suggest that our instruments are good at predicting endogenous regressors. Finally, in addition to the requirement that instrumental variables be correlated with the endogenous regressors, the instruments must also be uncorrelated with the structural error term. If (as is our case) the model is overidentified, meaning that the number of additional instruments exceeds the number of endogenous regressors, then we can test whether the instruments are uncorrelated with (i.e. orthogonal to) the error term. Results of that test are reported at the very end of Table 6 . The null hypothesis is that all instruments are uncorrelated with the sample-equivalent of the error term. And in our case it appears very likely (prob $>.8$ ). We thus verify the second condition for our instruments to be considered as valid.

Our last set of econometric results are reported in Table 8 and correspond to the implementation of the ACF 2-step estimator (see Appendix or Vandenberghe et al. 2013). They also allow us to reproduce the key OLS results of Tables 5, 6 or those obtained with IV-GMM and reported in Table 7. We confirm that there is a statistically significant complementarity between master's-educated workers and firms' proximity to frontier PTF. We find estimated form $\eta^{\text {mast }}=0.266$ for th Cobb-Douglas specifiation and 0.146 for the Translog. The corresponding coefficient for bachelor's-educated or secondary-educated workers are systematically smaller and not statistically significant. Suggesting that they play a much less decisive role in generating efficiency gains closer to the efficiency frontier. 
Table 8 The contribution to 1-year efficiency growtha ${ }^{b}$ of educated workers, according to the proximity to frontier. $\mathrm{ACF}^{\mathrm{a}-}$ GMM estimates for Eq. (4) (cluster-robust ${ }^{\mathrm{c}}$ standard errors). The STATA frontier command was use to generate the SF-estimated values for the proximity to frontier

\begin{tabular}{|c|c|c|}
\hline & Cobb-Douglas SF-by industry ${ }^{\mathrm{d}}$ & Translog SF-by industry ${ }^{\mathrm{d}}$ \\
\hline$\widehat{p t f}_{i t-1}$ & $\begin{array}{l}-0.410 * * * \\
(0.0437)\end{array}$ & $\begin{array}{l}-0.456^{* * * *} \\
(0.0559)\end{array}$ \\
\hline$S E C_{i t-1}$ & $\begin{array}{l}0.001 \\
(0.0116)\end{array}$ & $\begin{array}{l}0.009 \\
(0.0197)\end{array}$ \\
\hline$B A C H_{i t-1}$ & $\begin{array}{l}0.004 \\
(0.0124)\end{array}$ & $\begin{array}{l}0.020 \\
(0.0214)\end{array}$ \\
\hline$M A S T_{i t-1}$ & $\begin{array}{l}0.065^{*} \\
(0.0263)\end{array}$ & $\begin{array}{l}0.052 \\
(0.0300)\end{array}$ \\
\hline$\widehat{p t f}_{i t-1} \cdot S E C_{i t-1}\left[\eta^{\sec \text { ond }}\right]$ & $\begin{array}{l}-0.008 \\
(0.0520)\end{array}$ & $\begin{array}{l}0.029 \\
(0.0636)\end{array}$ \\
\hline$\widehat{p t f}_{i t-1} . B A C H_{i t-1}\left[\eta^{b a c h}\right]$ & $\begin{array}{l}0.005 \\
(0.0426)\end{array}$ & $\begin{array}{l}0.025 \\
(0.0691)\end{array}$ \\
\hline$\widehat{p t f}_{i t-1} \cdot M A S T_{i t-1}\left[\eta^{\text {mast }}\right]$ & $\begin{array}{l}0.226^{*} \\
(0.1078)\end{array}$ & $\begin{array}{l}0.146^{*} \\
(0.0612)\end{array}$ \\
\hline Controls & $\begin{array}{l}\text { yearXindustry(NAICS 2-digit), } \\
\text { province, year of incorporation, } \\
\text { change of educational mix } \\
\left(\triangle S E C_{i t} ; \triangle B A C H_{i t} ; \triangle M A S T_{i t}\right)\end{array}$ & $\begin{array}{l}\text { yearXindustry(NAICS } \\
\text { 2-digit), province, year of } \\
\text { incorporation, change of } \\
\text { educational mix }\left(\triangle S E C_{i t} \text {; }\right. \\
\left.\triangle B A C H_{i t} ; \triangle M A S T_{i t}\right)\end{array}$ \\
\hline Nobs (firmsXyear) & 89,556 & 89,556 \\
\hline Nfirms & 39,901 & 39,901 \\
\hline $\mathrm{R}^{2}$ & 0.44 & 0.44 \\
\hline $\operatorname{prob} \eta^{\text {mast }}=\eta^{\text {bach }}$ & 0.0689 & 0.1189 \\
\hline prob $\eta^{\text {mast }}=\eta^{\text {second }}$ & 0.0024 & 0.0041 \\
\hline prob $\eta^{\text {bach }}=\eta^{\text {second }}$ & 0.8518 & 0.9494 \\
\hline
\end{tabular}

Estimates obtained using Bel-first firm-level data (2008-2014)

$* p<0.05 ; * * p<0.01 ; * * * p<0.001$

aThe essence of this method is to use some function of a firm's consumption of intermediates [here the firm's total purchase of intermediates and services] to control for/proxy time-varying efficiency developments that are (partially) anticipated by the firms and correlated with the observed level of education (see Appendix for a full exposition of the ACF 2-steps estimator)

${ }_{p t f}-\widehat{p t f}_{i t-1}$

${ }^{\mathrm{c}}$ Standard errors are computed to account for firm-level clustering (correlation of error terms)

dNAICS 2-digit

\section{Conclusion}

There is plenty of individual-level evidence, based on the estimation of Mincerian equations, showing that better-educated individuals earn more, presumably because they are more productive. Many macroeconomists (Mankiw et al. 1992), analysing cross-country time series, also support the idea that the continuous expansion of edu- 
cation has contributed positively to growth by raising productivity. ${ }^{9}$ There is also a relatively vast empirical literature on the effects of human capital on firms' productivity. Using matched employer-employee data sets, Vandenberghe and Lebedinski (2014) for Belgium, Turcotte and Rennison (2004) for Canada, Fox and Smeets (2011) for Denmark, Abowd et al. (1999) for France, Galindo-Rueda and Haskel (2005) for the UK, Haltiwanger et al. (2007) for the United States, and Van Biesebroeck (2011) for Zimbabwe all find positive effects of workers' skills on firm/plant productivity. But this paper tries to go way beyond simply showing that education matters for firms' productivity.

The key idea here is to assess the role of different levels of educational attainment in fostering efficiency at different distances of the technological frontier; and to do that using firm-level panel evidence. This is something that, to our knowledge, has rarely been done before. Vandenbussche et al. (2006) and Aghion et al. (2009) using much more aggregate data have shown that when economies operate close to the productivity frontier, their ability to generate productivity growth rests on advanced forms of education. The idea underpinning the present paper is that something that has been observed for OECD countries (Vandenbussche et al. 2006) or US states (Aghion et al. 2009) should also be visible at much more disaggregated level; that of firms. To that purpose, we analyse a rich panel of firms forming the private-for-profit Belgian economy, covering the 2008-14 period.

The results of this paper are essentially twofold. First, the paper shows that the 'national' frontier - and within a particular country the industry frontier-plays a role in fostering convergence, and that advanced forms of education play a complementarity role at that level. That result can be visualised on Fig. 4, left-hand axis. Their contribution to efficiency growth among "laggards" is much smaller (on Fig. 4, thick solid lines are negatively slopped when going from right to left). Our Belgian firm-level panel data strongly support the idea that workers with advanced types of education contribute more to efficiency gains when they work inside firms situated closer to the national/industry efficiency frontier. So far, the empirical literature had emphasised this result in reference to the international/global frontier. The fact that we are able to replicate that results with a much more "local" frontier might come as a surprise to people who believe that small advanced economies like Belgium-and the industries inside it - are relatively homogeneous in terms of efficiency and educational attainment of the workforce. It is probably less to people who have been working with within country/firm-level data, and have quantified the (important) heterogeneity that exists at the level.

The second key result is that complementarity is significantly stronger for master'seducated workers than their bachelor's- or upper-secondary-educated peers. Our results suggest that master's/ISCED ${ }^{10} 7$ clearly dominate bachelor's/ISCED 6 degrees when it come to fostering efficiency gains close to the frontier. While the existing

\footnotetext{
9 The role of education as a net contributor to country-level growth is in fact more disputed than its contribution to individuals' fortune (see Sianesi and van Reenen (2003); de la Fuente and Doménech (2006) for surveys). This is due to the methodological difficulties related to measuring skills and, what is more, modelling and identifying the channels through which skills impact on macroeconomic performance.

10 The International Standard Classification of Education (ISCED) developped by UNESCO and OECD (for more details see http://uis.unesco.org/sites/default/files/documents/international-standard-classificatio n-of-education-isced-2011-en.pdf.)
} 


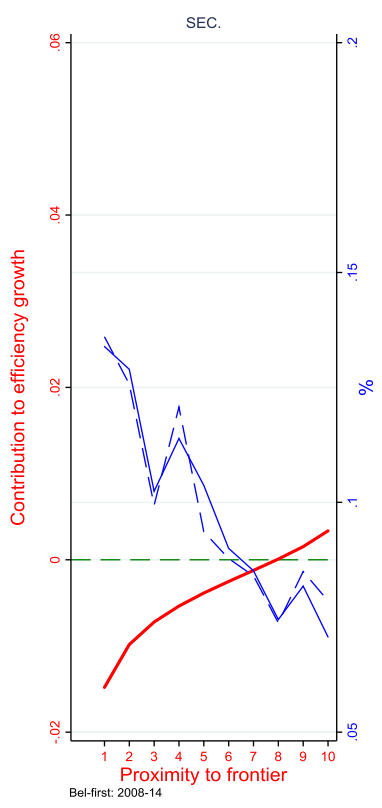

Marginal impact of education
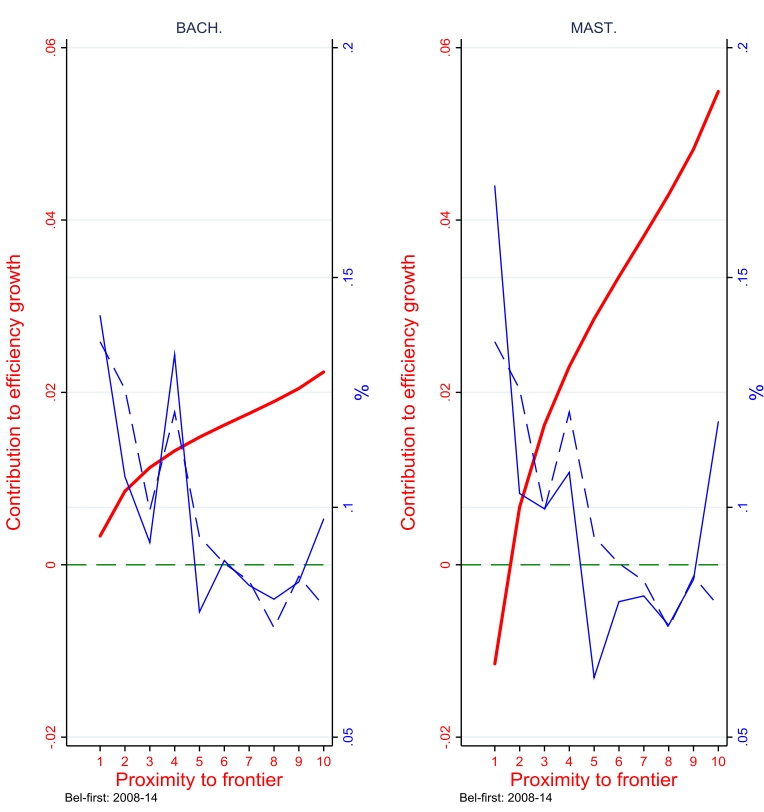

$\%$ educated workers

$\%$ all workers

Fig. 4 Marginal impact of educated workers ${ }^{\mathrm{a}}$ on annual efficiency growth [left-hand vertical axis] according to the proximity to frontier ${ }^{b}$ decile [horizontal axis] + frequency distribution [right-hand vertical axis] of educated workers vs all workers ${ }^{\mathrm{c}}$

${ }^{a}$ The left-hand vertical axis measures the impact on annual firm-level efficiency growth of a $100 \%$-points rise of the share of educated workers. The values are computed using the OLS estimation of Eq. (7)—see coefficients reported in Table 5, The closer the firm to the frontier the larger the positive productivity growth and below a certain threshold that contribution is even negative. The right-hand axis (and the two frequency curves) measures the distribution of the workforce according to the distance to the efficiency frontier of the firm they work in

${ }^{b}$ The frontier is industry-specific (i.e. NAICS 2-digit) and specified as a Translog. It has been estimated using stochastic frontier methods (SF) exposed in Sect. 2

${ }^{\mathrm{c}}$ The dashed blue line (common to the 3 sub-figures) corresponds to the overall distribution of the workforce along the proximity-to-frontier axis. The solid blue lines inform about the distribution of the different categories of educated workers (secondary-, bachelor's or master's-educated). When the solid line is above the dashed one, it means that the educated workers are overrepresented, and vice versa

Estimates obtained using Bel-first firm-level data (2008-2014). (Color figure online)

empirical literature on distance-to-frontier and education concludes that it is crucial to distinguish between the two margins that are primary/secondary versus tertiary educational attainment [with only the latter type of education being a significiant source of convergence closer to the international frontier], we conclude that [within the context of a relatively advanced economy like Belgium] it might also be important to distinguish bachelor's vs master's. These two results accord with idea that innovation (i.e. which is presumably how firms improve performance when they start approaching the frontier) is a relatively more skill-intensive activity than imitation or replication and that only. The second one also suggests that, in the context of relatively advanced 
economies like Belgium, only workers who have been exposed to a master's/ISCED 7 education within tertiary education possess those skills. This result may have (educational) policy implications.

Note finally that our results raise the question of the optimal allocation of workers with master's across firms and industries. Should policies aimed at boosting efficiency growth foster the mobility of more educated workers towards "frontier" entities? Moving more workers with master's to firms closer to the efficiency frontier would have a large impact on productivity. At the $10^{\text {th }}$ decile of the proximity-to-frontier distribution, we estimate that a $10 \%$-point increase in the share of these workers [a big increment that would double the current share] could raise annual efficiency growth by up to $5.5 \%$ points (Fig. 4, right-hand figure). The size of the effect declines the further the firm is from the technological frontier. Around the 5th decile of the proximity-to-frontier distribution, the equivalent gains falls below $2 \%$-points.

Is there evidence that these individuals do not spontaneously concentrate in firms close to the frontier, where they are more productive? This evidently calls for future research investigating labour (re)allocation mechanisms. But Fig. 4 contains some preliminary elements of answer about the adequacy of workers' current allocation. The dashed line (common to the 3 sub-figures) corresponds to the overall distribution of the workforce along the proximity-to-frontier (PTF) axis. The fact that it is not horizontal (and equal to 0.1 ) reflects the unequal distribution of firm size along the PTF distribution. ${ }^{11}$ The solid thin lines inform about the distribution of each category of educated workers (secondary-, bachelor's- or master's-educated). When the solid thin line is above the dashed one, educated workers are overrepresented and vice versa. The good news, in the case of Belgium, is that master's-educated workers are clearly overrepresented among "frontier" firms; which is precisely where they contribute the most to efficiency gains. Still, many of them work in "laggard" firms.

\section{Appendix: The ACF-GMM Estimator}

Considering a stylised version our Stage 2 model Eq. (7),

$$
y_{i t}=X_{i t} \lambda+\varepsilon_{i t}
$$

with

$$
\begin{aligned}
y_{i t} & \equiv \widehat{p t f}_{i t}-\widehat{p t f}_{i t-1} \\
X_{i t} & =\left[p f t_{i t-1}, S E C_{i t-1} ; B A C H_{i t-1} ; M A S T_{i t-1} ; S E C_{i t-1} \text { pft }_{i t-1} ; B A C H_{i t-1} \text { pft }_{i t-1} M_{\text {MSST }} \text { it-1 }_{\text {pft }} t_{i t-1}\right] \\
\lambda & \equiv\left[\alpha, \beta, \gamma_{1}, \gamma_{2}, \gamma_{3}, \eta_{1}, \eta_{2}, \eta_{3,}, \theta\right]
\end{aligned}
$$

\footnotetext{
11 And Fig. 4 suggests that larger firms (with more employees) are overrepresented among "frontier" firms (i.e. they form the 6th to 10th decile of the PTF distribution) whereas smaller sizes are predominant among "laggards".
} 
the logic of the ACF-GMM estimator is to consider that the error term comprise $\varepsilon_{i t}$ a time-varying unobserved terms (partially known or anticipated by the management of the firm) $\omega_{i t}$ that is potentially correlated with the other regressors. It might for instance correspond to a (positive/negative) efficiency development influencing their educational mix.

$$
\varepsilon_{i t}=\omega_{i t}+\sigma_{i t}
$$

Key with ACF it to assume that firms' (observable) demand for intermediate inputs $\left(\right.$ int $\left._{i t}\right)$ is a function of $\omega_{i t}$ as well as labour inputs (here the shares of workers by educational attainement):

$$
i n t_{i t}=f_{t}\left(\omega_{i t}, X_{i t}\right)
$$

ACF further assume that this function $f_{t}$ is monotonic in $\omega_{i t}$ and its other determinants, meaning that it can be inverted to deliver an expression of $\omega_{i t}$ as a function of $i n t_{i t}$, $X_{i t}$ and introduced into the model

$$
y_{i t}=X_{i t} \lambda+f_{t}^{-1}\left(i n t_{i t}, X_{i t}\right)+\sigma_{i t}
$$

The ACF algorithm consists of two steps. In step one, outcome variable (here efficiency growth) is regressed on a composite term $\Phi_{i t}$ that comprises a constant, and 3rd order polynomial expansion in $i$ int $_{i t}, X_{i t}$, approximating $f_{t}^{-1}\left(i n t_{i t}, X_{i t}\right)$

$$
y_{i t}=\Phi_{i t}\left(i n t_{i t}, X_{i t}\right)+\sigma_{i t}
$$

At that point $\lambda$ is clearly not identified yet. The first-step regression delivers an unbiased estimate of the composite term $\Phi_{i t}^{\text {hat }}$; i.e. outcome net of the purely random term $\sigma_{i t}$. This is done at step 2. Key is the idea that one can generate implied values for $\omega_{i t}$ using first-stage estimates $\Phi_{i t}^{\text {hat }}$ and candidate values for the vector of coefficients $\lambda$

$$
\omega_{i t}=\Phi_{i t}^{h a t}-X_{i t} \lambda^{\$}
$$

ACF assume further that the evolution of $\omega_{i t}$ follows a first-order Markov process

$$
\omega_{i t}=E\left[\omega_{i t \mid} \omega_{i t-1}\right]-\xi_{i t}
$$

That assumption simply amounts to saying that the realization of $\omega_{i t}$ depends on some function $\mathrm{g}($.) (known by the firm) of $t-1$ realisation and an (unknown) innovation term $\xi_{i t}$.

$$
\omega_{i t}=g\left(\omega_{i t-1}\right)+\xi_{i t}
$$


By regressing non-parametrically (implied) $\omega_{i t}$ on (implied) $\omega_{i t-1}, \omega_{i t-2}$, one gets residuals that correspond to the (implied) $\xi_{i t}$ that can form a sample analogue to the orthogonality (or moment) conditions identifying $\lambda \equiv\left[\alpha, \beta, \gamma_{1}, \gamma_{2}, \gamma_{3}, \eta_{1}, \eta_{2}, \eta_{3}, \theta\right]$.

$$
\mathrm{E}\left[\xi_{i t \mid} X_{i t}\right]=0
$$

with the possibility, for some of the variables forming $\mathrm{X}_{i t}$ to resort to lagged values, under that assumption that these are less likely to be uncorrelated with the innovation terms $\xi_{i t}$. We followed this recommendation for the variables containing education share, meaning that our moment conditions are

$$
\begin{gathered}
\mathrm{E}\left[\xi_{i t \mid} S E C_{i t-2}, S E C_{i t-3} \ldots\right]=0 \\
\mathrm{E}\left[\xi_{i t \mid} B A C H_{i t-2}, B A C H_{i t-3} \ldots\right]=0 \\
\mathrm{E}\left[\xi_{i t \mid} M A S T_{i t-2}, M A S T_{i t-3} \ldots\right]=0 \\
\mathrm{E}\left[\xi_{i t \mid} S E C_{i t-2}, S E C_{i t-3} \ldots\right]=0 \\
\mathrm{E}\left[\xi_{i t \mid} B A C H_{i t-2}, B A C H_{i t-3} \ldots\right]=0 \\
\mathrm{E}\left[\xi_{i t \mid} M A S T_{i t-2}, M A S T_{i t-3} \ldots\right]=0
\end{gathered}
$$

\section{References}

Abowd, J. M., Kramarz, F., \& Margolis, D. N. (1999). High wage workers and high wage firms. Econometrica, 67(2), 251-334.

Acemoglu, D., Aghion, P., \& Zilibotti, F. (2006). Distance to frontier selection, and economic growth. Journal of the European Economic Association, 4, 37-74.

Ackerberg, D. A., \& CavesK, Frazer G. (2015). Identification properties of recent production function estimators. Econometrica, 83, 2411-2451.

Aghion, P., Boustan, L., Hoxby, C., \& Vandenbussche, J. (2009). The causal impact of education on economic growth: evidence from united states. In D. Romer \& J. Wolfers (Eds.), Brookings papers on economic activity: conference draft. Washington, DC: Brookings.

Aghion, P., \& Howitt, P. (1992). A model of growth through creative destruction. Econometrica, 60, 323-351.

Aigner, D. J., Lovell, C. A. K., \& Schmidt, P. (1977). Formulation and estimation of stochastic frontier production function models. Journal of Econometrics, 6, 21-37.

Andrews, D., Criscuolo, C., \& Gal P. (2015). Frontier firms, technology diffusion and public policy: micro evidence from OECD countries. OECD Productivity Working Papers 2.

Barro, R., \& Sala-i-Martin, X. (1997). Technological diffusion, convergence and growth. Journal of Economic Growth, 2, 1-26.

Bartelsman, E., Dobbelaere, S., \& Peters, B. (2015). Allocation of human capital and innovation at the frontier: firm-level evidence on Germany and the Netherland's. Industrial and Corporate Change, 24(5), 875-949.

Bartelsman, E. J, Haskel, J., \& Ralf M. (2008). Distance to which frontier? Evidence on productivity convergence from international firm-level data. CEPR Discussion Papers 7032

Chambers, R. G. (1988). Applied production analysis: A dual approach. Cambridge: Cambridge University Press.

de la Fuente, A., \& Doménech, R. (2006). Human capital in growth regressions: how much difference does data quality make? Journal of the European Economic Association, 4(1), 1-36.

Dumont, M., \& Kegels, C. (2016). Young firms and industry dynamics in Belgium. Federal Planning Bureau Working Papers, 1606, Belgium.

Fox, J., \& Smeets, V. (2011). Does input quality drive measured differences in firm productivity? International Economic Review, 52(4), 961-989. 
Fuss, M., McFadden, D., \& Mundlak, Y. (1978). A survey of functional forms in the economic analysis of production. In Production economics: a dual approach to theory and applications, North-Holland, under the direction of Melvin Fuss et Daniel McFadden.

Galindo-Rueda, F., \& Haskel J. (2005). Skills, workforce characteristics and firm-level productivity: Evidence from the matched ABI/Employer skills survey. IZA Discussion Paper 1542. IZA: Bonn

Haltiwanger, J., Lane, J., \& Spletzer, J. (2007). Wages, productivity, and the dynamic interaction of businesses and workers. Labour Economics, 14(3), 575-602.

Howitt, Peter. (2000). Endogenous growth and cross-country income differences. American Economic Review, 90, 829-846.

Mankiw, G., Romer, D., \& Weil, D. (1992). A contribution to the empirics of economic growth. Quarterly Journal of Economics, 107(2), 407-437.

Meeusen, W., \& van den Broeck, J. (1977). Productivity estimation from Cobb-Douglas production functions with composed error. International Economic Review, 18, 435-444.

Nelson, R., \& Phelps, E. (1966). Investment in humans, technological diffusion, and economic growth. The American Economic Review, 56, 69-75.

Ouimet, P., \& Zarutskie, R. (2014). Who works for startups? The relation between firm age, employee age and growth. Journal of Financial Economics, 112, 386-407.

Sianesi, B., \& van Reenen, J. (2003). The returns to education: macroeconomics. Journal of Economic Surveys, 17(2), 157-200.

Syverson, C. (2011). What determines productivity? Journal of Economic Literature, 49(2), 326-365.

Turcotte, J., \& Rennison, L. W. (2004). The link between technology use, human capital, productivity and wages: firm-level evidence. International Productivity Monitor, 9(Fall), 25-36.

Van Biesebroeck, J. (2011). Wages equal productivity. Fact or fiction? Evidence from SubSaharan Africa. World Development, 39(8), 1333-1346.

Vandenberghe, V., \& Lebedinski, L. (2014). Assessing education's contribution to productivity using firmlevel evidence. International Journal of Manpower, 35(8), 1116-1139.

Vandenberghe, V., Rigo, M., \& Waltenberg, F. (2013). Ageing and employability. Evidence from belgian firm-level data. Journal of Productivity Analysis, 40(1), 111-136.

Vandenbussche, J., Aghion, P., \& Meghir, C. (2006). Distance to frontier, growth, and the composition of human capital. Journal of Economic Growth, 11(2), 97-127. 